\title{
An ENGINEERING DESIGN COURSE TO DEVELOP AND ASSESS Critical Thinking and Problem Solving
}

\author{
Ryan P. Mulligan, Natalie Simper, and Nerissa Mulligan \\ Queen's University, Kingston, Ontario, Canada \\ ryan.mulligan@queensu.ca
}

\begin{abstract}
A challenging new engineering design course is developed as part of the Engineering Design and Practice Sequence in the Civil Engineering program. This course engages students in a cyclical design process where they plan, build, test, and evaluate a model-scale tidal current turbine. They then use their own observations and analysis to iteratively inform, improve and re-test their design.

The two objectives of this paper are to provide a description of the development and structure of this design course, and to assess student learning. The Final Design Reports were externally evaluated using the Valid Assessment of Learning in Undergraduate Education rubrics. Students also completed a standardized test called the Collegiate Learning Assessment as an objective evaluation of longitudinal learning gains. The Civil Engineering students demonstrated significant improvement in critical thinking, problem solving, and written communication skills.
\end{abstract}

Keywords: Engineering design, assessment of learning, marine renewable energy, tidal current turbines

\section{INTRODUCTION}

The process of creating a new design necessitates the application of technical knowledge, and also requires creative thinking, concept development, selection of options, iterative testing, decision making and communication. This makes the design process challenging to teach, and it is common practice to have students learn these methods with a hands-on approach by completing a major project in the area of study. For example, students could complete a design project where the aim is to evaluate the environmental impacts associated with the design of a water transmission pipeline [1]. In another field, learning can be achieved by students considering joint structural and geotechnical problems in the design of an office building [2].

At Queen's, engineering students acquire and apply engineering design skills through a series of specialized courses that run through the 4-year curriculum. In the Engineering Design and Practice Sequence (EDPS) courses students learn by conducting design projects. In addition to design process methods and tools, these courses include problem analysis, creativity, economics and entrepreneurship, engineering communications, professionalism, and ethics [3]. In Civil Engineering, a new third-year course has been developed to complete the EDPS, called CIVL 360: Civil Engineering Design and Practice. In this course students address a major problem facing society today: how to harness marine renewable energy $[4,5]$. They achieve this by planning, building, testing, and evaluating a model-scale tidal current turbine. They then iteratively improve their design and produce a Final Design (FD) Report that communicates the results related to their FD, and all stages of the design process that were completed on the path toward the FD.

In this paper, we describe the development and structure of the CIVL 360 Design course and we evaluate student learning using well documented cognitive assessment tools. Learning is assessed using the Collegiate Learning Assessment (CLA+) and the Valid Assessment of Learning in Undergraduate Education (VALUE) rubrics. These are used to gauge student demonstrations of critical thinking, problem solving, and written communication skills elicited through the process of completing their FD Report.

\section{DESIGN COURSE DEVELOPMENT}

The goal of this new course is for third-year civil engineering students to develop and use engineering skills to resolve a complex, open-ended design task that involve the iterative application of technical knowledge to identify and evaluate design options. The students were presented with the task of designing, building and testing a scale model of a turbine for extraction of energy from tidal currents. The design project was completed by guiding the students through the stages of the design process with "subreport" (SR) deliverables due at each stage. The phases of the project related to stages of the design process, as illustrated in Figure 1. 


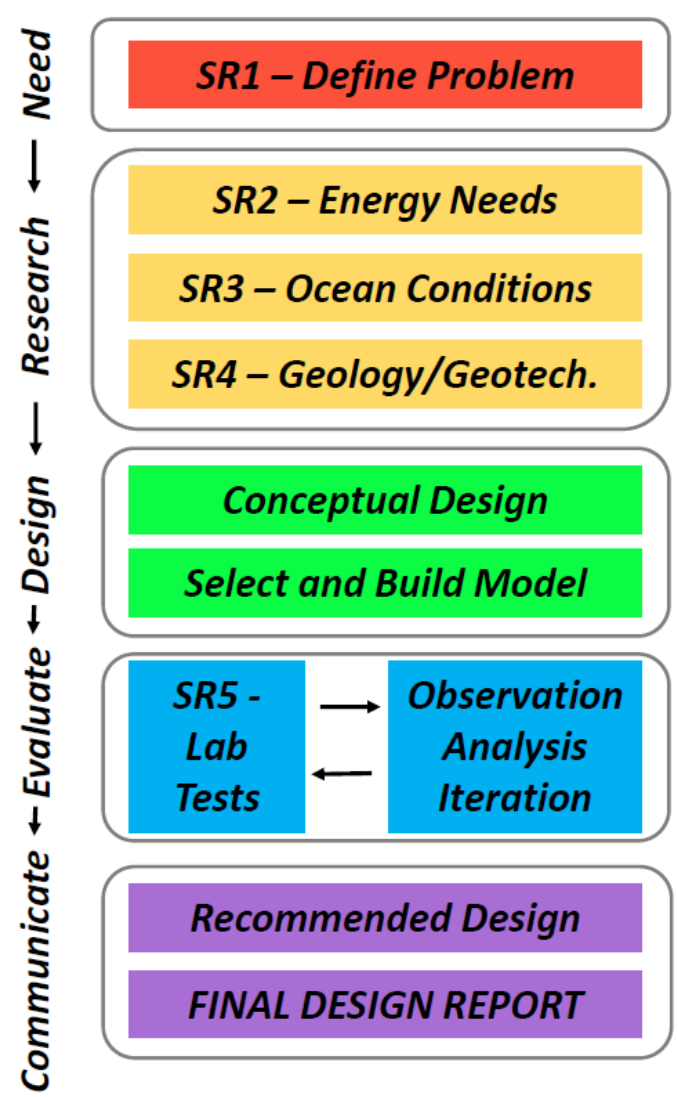

Fig. 1. Stages in the engineering design process as applied to CIVL 360, and the sub-report (SR), and final report deliverables in the course.

\subsection{Problem Definition}

Engineering problems arise due to a societal need, so in SR1 the goal is to define the problem. To achieve this, students research and discuss the "big picture". Students are asked: why is renewable energy important to society and how can a new design influence our future energy use? They must point out the importance of the problem, and provide motivation for the effort needed to solve it.

\subsection{Research}

Before creating a new or modified design, the students brainstormed ideas for a tidal current energy extraction. They began by looking into existing designs. This may have included conceptual designs, or designs that had been built and tested in field conditions. This necessitated research into several different areas.

In SR2, the students defined energy needs by comparing different existing tidal turbine designs. They show and explained the design choices that they made, and put each design into perspective by comparing the energy production. They then discussed the initial design concepts and ideas, by addressing the questions: What existing design ideas will you incorporate? What should be avoided or improved? They start thinking about design constraints for their design by selecting a "test site" somewhere in the world and researching the energy needs, marine conditions, and constraints imposed by selecting this location.

In SR3, each group investigated the marine conditions of the site they selected, and therefore assessed the energy resources and determined the required criteria for their design. These criteria were dependent on the relevant tidal conditions for the site, such as the amplitudes and phases of the water levels and currents. Other considerations for the evaluation of criteria were the water depth, distance to the power grid, and storm conditions.

The goal in SR4 is to plan for the safe and stable location of the turbine at the field scale. For this, the students investigated the site geology and geotechnical conditions, and calculated the force needed to stabilize the turbines at the base on the seabed. This part of the report included a description of the geological conditions and seabed slopes at the test site by considering the larger area and selecting an exact test site. They also considered the geotechnical properties of the seabed, particularly the critical shear stress of erosion for the marine sediments on the seabed and yield stress in the sediment column. This information was used to design the base of the structure, and quantitatively describe the design for stability of the turbine as appropriate to the particular site. Students could choose to design a gravity base, use vertical piles or a moored floating structure with anchors and chains. Each group determined the lift and drag forces on the turbine blades, computed the moment about the base imposed by the current, and calculate the depth of penetration of a pile to resist this moment. Students justify parameter selections and show sample calculations with the appropriate conditions for the test site.

\subsection{Design}

"Design" permeates through the course and at this stage the students continue through the process by developing a list of design constraints, a conceptual design description and drawings. They build on the background, research, and preliminary design calculations they have already completed and consider questions posed to them at the start of the project including:

- What constraints/limitations are imposed on the design?

- Which are most important and why?

- How will they influence your design?

- Are these site dependent?

- Who are the stakeholders? 
These issues were addressed for both the field (full scale) and lab (model scale) turbines. Students then sketched their primary design and design alternatives to clearly show the overall concept, shape, and orientation. The conceptual drawings were completed neatly by hand or using a computer, and accompanied by description of the features including the geometry, size, scale, and operation under the design conditions.

A key aspect of the design process was the production of scale models, and testing in the laboratory. For the models, many student groups design turbines using SolidEdge software. This enables the design drawings and digital rendering to be used to build a plastic model, such as the example shown in Figure 2, using the 3D printer available in the Faculty of Engineering and Applied Science.
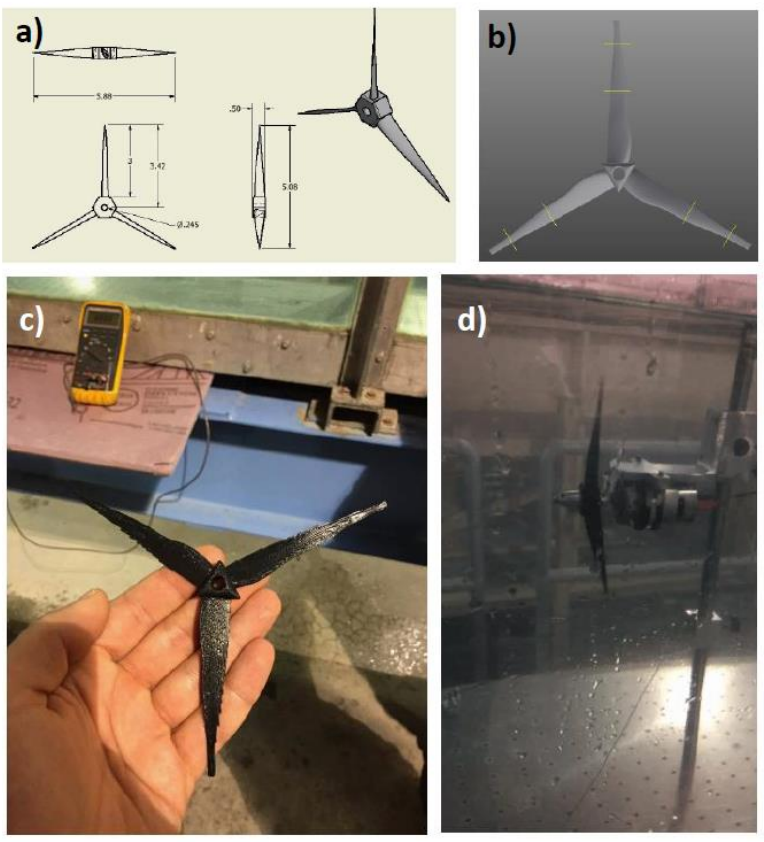

Fig. 2. Tidal turbine design by a student group: a) design drawings; b) computer rendering; c) 3D-printed plastic model; d) testing in the flume.

\subsection{Model Evaluation}

Using the tilting flume at the Coastal Engineering Lab, students tested their models by connecting them to small power generators that operate underwater. These were connected to a voltmeter, enabling the voltage generated by rotation of the turbine to be measured. These voltage measurements were used as the primary indicator of design performance. The underwater motion of each model was also visually inspected to qualitatively describe the rotation and generation of any turbulent motion of the fluid around the blades. The models were tested for a range of current speeds, simulating the changes in flow that occurred over a tidal cycle in the ocean. After these observations, students made design modifications in order to improve performance, and continued to iteratively improve their designs. The SR5 deliverable required the student groups to describe the scale model, discuss iterations compared to the initial design, and communicate the test results obtained in the laboratory.

\subsection{Communication}

Once students enter the workforce, communication through technical writing, design graphics, and oral presentations is a primary element of providing information to clients and stakeholders. Effective communication is key component at each stage of the design process. This course culminated with the submission of a Final Design (FD) report, complete with design drawings, a table of specifications, and the turbine models produced during the design process. In the FD report, students combine the sub-reports into one document, after receiving feedback at each stage from the professor and teaching assistants. For the final report, each subsection is edited for continuity and new sections are added that provide discussion of the final design including final lab test results, detailed design drawings of the final model as well as conclusions and recommendations for future work. The final reports were assessed using a rubric developed for the course.

\section{LEARNING ASSESSMENTS}

\subsection{Assessment Tools and Sample}

CIVL 360 was one of the courses involved in the Queen's University Learning Outcomes Assessment Consortium (LOAC) project, a longitudinal study investigating critical thinking, problem solving and written communication. Two of the key tools utilized in the project were the Collegiate Learning Assessment (CLA+) [6] and the Valid Assessment of Learning in Undergraduate Education (VALUE) rubrics [7].

The CLA+ is a 90-minute online test developed by the Council for Aid to Education (CAE). It is presents students with a real-world situation with supporting material that students must use to address a problem, identify a solution, provide conclusions and recommendations. The test is scored by an automated system using a validated rubric, with the total score calculated based on sub-scores of analysis and problem solving, written effectiveness and mechanics, quantitative reasoning, critical reading and evaluation, and critiquing an argument.

The VALUE Rubrics were developed by the American Association of Colleges and Universities, and are broad, 
discipline-neutral descriptions of learning outcomes There are 16 rubrics relating to essential learning outcomes, with four levels of performance criteria, from the benchmark level of a student entering university to the capstone level of a student who has just completed their undergraduate experience. The performance criteria are aimed evaluation of summative displays of student learning.

Project researchers recruited $n=32$ of the 94 students in the CIVL360 course to participate in the research and have their scores on the CLA+ and their FD Reports scored on the VALUE rubrics. Similar recruitment was conducted courses from other Engineering departments. The in firstyear $(n=203)$, second-year $(n=145)$ and third-year $(n=$ 65). Testing was conducted within the first five weeks of the academic year, in participating courses, for each year of the study.

\subsection{Assessment Results}

Univariate analysis of variance (ANOVA) was applied to investigate any significant differences for CLA+ total score between performance by the Civil students and those from other engineering disciplines. In this analysis, $F$ values are the ANOVA results and $p$ is a significance value calculated at the $95 \%$ confidence interval. Table 1 displays descriptive statistics for the sample of Civil Engineering and the comparative sample from other Engineering departments (Chemical, Computer and Electrical, Engineering Physics, Geological, Math, Mechanical, and Mining Engineering). Separate analysis of variance was conducted for the first, second, and thirdyear results.

Table 1: CLA+ descriptive statistics

\begin{tabular}{lccccccc}
\hline & \multicolumn{3}{c}{ Civil sample } & & \multicolumn{3}{c}{ Other Engineering } \\
\cline { 2 - 3 } \cline { 6 - 8 } & $\mathrm{n}$ & Mean & SD & & $\mathrm{n}$ & Mean & SD \\
\hline $\begin{array}{l}\text { 1st } \\
\text { year }\end{array}$ & 31 & 1172.2 & 93.5 & & 203 & 1170.7 & 112.1 \\
$\begin{array}{l}\text { 2nd } \\
\text { year }\end{array}$ & 30 & 1152.9 & 114.4 & & 145 & 1161.0 & 114.7 \\
$\begin{array}{l}\text { 3rd } \\
\text { year }\end{array}$ & 31 & 1205.1 & 106.1 & & 65 & 1144.1 & 127.6 \\
\hline
\end{tabular}

The first-year Civil Engineering performance was not significantly different to the sample of peers in other departments $(F(1,233)=0.005, p=0.95)$. There was a similar outcome in second-year, but by third-year, the Civil students perform significantly better than the sample from the other departments $(F(1,95)=5.32, p=0.02)$. Figure 3 displays the comparative performance on the CLA+ of the first three years of their engineering programs. The effect of year group on CLA+ Total score for the Civil engineering students was $d=0.33\left(d=m_{3}-m_{1} /\right.$ pooled SD $)$.

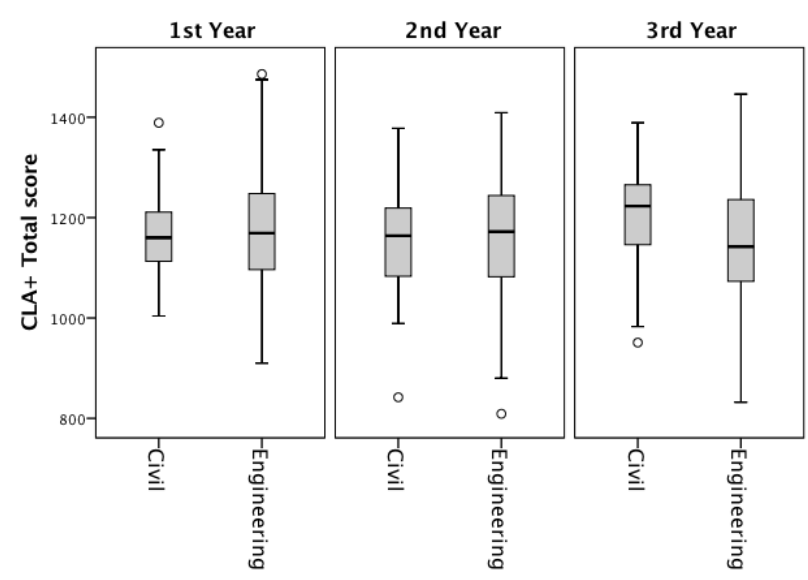

Fig. 3. CLA+ total score box plots for civil engineering compared with the sample from the other engineering disciplines at Queen's.

That is to say the Civil engineering students demonstrated $1 / 3$ of a standard deviation improvement between first and third-year.

The VALUE rubrics were used to investigate performance of critical thing and problem solving specifically in the third-year civil course. The VALUE rubrics contain general (not engineering specific) criteria for four performance levels. The rubrics designed for assessment across and through undergraduate programs. The Benchmark 1 level describes performance expectations associated with students in their first year of higher education, through to the Capstone 4 level describing target criteria for students completing their undergraduate programs.

The critical thinking and problem solving rubrics were used for evaluation of the FD Reports. The reports were independently scored by two research associates, who achieved above $90 \%$ agreement in their scoring. Figure 4 shows the assessment dimensions, and the percentage of the CIVL 360 sample scored at each level. For the FD Reports, $25 \%$ were scored at the highest possible level for defining the problem. This criterion requires that students have "Demonstrated the ability to construct a clear and insightful problem statement with evidence of all relevant contextual factors". The weakest area of critical thinking demonstrated in the reports was in the forming conclusions, with some of the students oversimplifying the consequences and outcomes. This may have been because the students were involved in an iterative process that took longer than expected, and they simply ran out of time, or were not yet ready to draw final conclusions.

Explanation of issues was the highest of the dimension outcomes, with $38 \%$ of the reports scored at the Capstone 4 level. The criterion for this level states that the "Issue/problem to be considered critically is stated clearly and described comprehensively, delivering all relevant information necessary for full understanding". 
VALUE dimensions- \% at each level

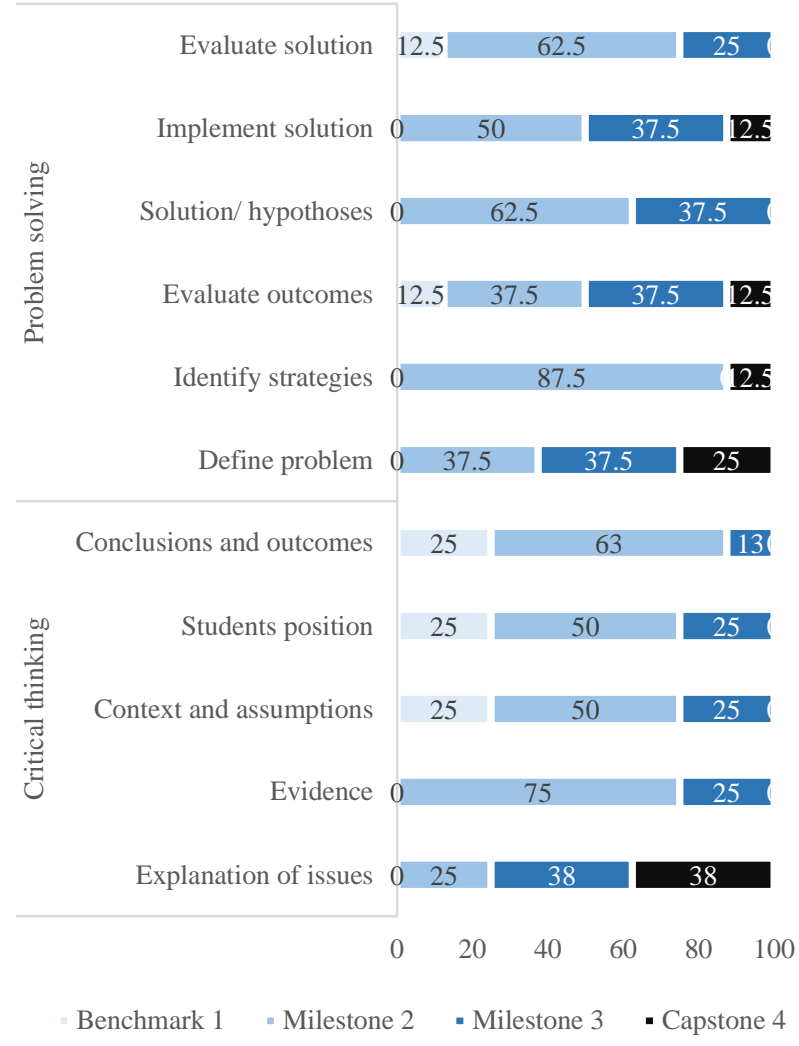

Fig. 4. FD Report scoring on the VALUE rubrics.

\section{DISCUSSION}

Critical thinking outcomes develop slowly, and gains are difficult to detect on the CLA+ [8]. The test was conducted part way through the term, so it is likely skills in the area of critical thinking and problem solving were successfully developed earlier in their civil program, manifesting in improvements demonstrated in the Civil third-year test scores. It is also important to recognize that there are differences in sample sizes, and the convenience sampling may have resulted in possible sample bias.

\section{SUMMARY AND CONCLUSIONS}

A new course was developed to complete the Engineering Design and Practice Sequence, and designed to develop the skills of critical thinking in civil engineering at Queen's University. In this course students consider the problem of how to harness marine renewable energy. This is achieved by planning, building, testing, evaluating, and iteratively improving a model-scale tidal current turbine. Students in the civil course performed significantly better than the other engineering departments on the CLA+, a standardized test of analysis and problem solving. The final design reports were externally evaluated using the Valid Assessment of Learning in Undergraduate Education rubrics. Overall, the student design groups demonstrated high levels of critical thinking, and problem solving. The results of this detailed assessment, and feedback through involvement in the Learning Outcomes Assessment Consortium project has helped to improve this important civil engineering design course.

\section{Acknowledgements}

We acknowledge funding from the Department of Civil Engineering and the efforts and feedback from the thirdyear civil engineering students at Queen's. The development of this course was improved with helpful discussions with Kent Novakowski, Richard Brachman, and David Noonan. We also recognize the Higher Education Quality Council of Ontario for their funding of the Queen's Learning Outcomes Assessment Consortium who conducted the rubric scoring included in this paper.

\section{References}

[1] Yves Filion, "Developing and teaching a course in "Applied sustainability and public health in civil engineering design" at Queen's University, Kingston, Canada", Journal of Professional Issues in Engineering Education and Practice, vol. 136, no. 4, pp. 197-205, 2010.

[2] K. Gavin, "Case study of a project-based learning course in civil engineering design", European Journal of Engineering Education, vol. 36., no. 6, pp. 547-558, 2011.

[3] David S. Strong and Brian Frank, "A novel facultywide approach to teaching second year engineering design and professional practice", Proc. CEEA Canadian Engineering Education Conf., CEEC12, Witold Kinsner (ed.) (Winnipeg, MB; 17-20 June 2012), 8 pp., 2012.

[4] Ryan P. Mulligan, Peter C. Smith, Paul S. Hill, Jing. Tao, and Danika van Proosdij, "Effects of tidal power generation on hydrodynamics and sediment processes in the upper Bay of Fundy", Proc. Canadian Society for Civil Engineering Annual Conference, CSCE 2013 (Montreal, QC; 29 May - 1 June 2013), 10 pp., 2013.

[5] Logan M. Ashall, Ryan P. Mulligan and Brent A. Law, "Variability in suspended sediment concentration in the Minas Basin, Bay of Fundy, and implications for changes due to tidal power extraction", Coastal Engineering, vol. 107, pp. 102-115, 2016. 
[6] Roger Benjamin, "Two questions about critical thinking tests in higher education". Change: the magazine of higher learning, vol. 46, no. 2., pp. 24-31, 2014.

[7] Terrel Rhodes and Ashlet Finley, Using the VALUE rubrics for improvement of learning and authentic assessment. Association of American Colleges \& Universities (AAC\&U), 44 pp., 2013 \{ISBN: 978-09890972-0-8\}

[8] Richard Arum and Josipa Roska, Academically adrift: Limited learning on college campuses. Chicago, IL: University of Chicago Press, 272 pp., 2011 \{ISBN: 9780226028569\} 